\title{
A curadoria de conteúdo digital enquanto proposta metodológica e multirreferencial
}

\author{
Alexandre Meneses Chagas ${ }^{1}$, Ronaldo Nunes Linhares ${ }^{1}$, Marlton Fontes Mota ${ }^{2}$ \\ profamchagas@gmail.com, nuneslinhares.ronaldo8@gmail.com, marltonmota@hotmail.com \\ ${ }^{1}$ Professor do programa de pós-graduação de Educação da Universidade Tiradentes, Aracaju, Sergipe, Brasil. \\ ${ }^{2}$ Doutorando do programa de pós-graduação de educação da Universidade Tiradentes, Aracaju, Sergipe, \\ Brasil.
}

DOI: $10.17013 /$ risti.33. 32-47

\begin{abstract}
Resumo: Esta pesquisa qualitativa adota a abordagem multirreferencial proposta por Ardoino (1990; 1993; 1998), com um olhar plural e heterogêneo acerca dos objetos pesquisados. Para tal, foi utilizada a curadoria de conteúdos digitais na educação enquanto prática docente. A curadoria de conteúdos digitais foi utilizada como forma de autorizar os alunos a se tornarem protagonistas no processo de aprendizagem. Tendo o objetivo de sugerir dispositivos metodológicos multirreferenciais para a identificação do perfil das competências informacionais dos discentes, do curso de Comunicação Social da Universidade Tiradentes, da disciplina Marketing I em 2017/1. Para tal, foi necessário fazer uso de alguns dispositivos como: uma atividade descritiva para resolução de problema; um questionário para identificar o perfil das competências informacionais; uma oficina e a prática inicial de curadoria de conteúdo. Como principal resultado, percebe-se um aluno com competências na realização de busca de conteúdos, fato que contribui na prática da curadoria de conteúdo digital.
\end{abstract}

Palavras-chave: curadoria de conteúdo; multirreferencial; cibercutura; investigação qualitativa.

\section{Digital content curation as a methodological and multi-referential proposal}

Abstract: This qualitative research adopts the multi-referential approach proposed by Ardoino (1990; 1993; 1998), with a plural and heterogeneous look about the researched objects. For this, digital content curation was used in education as a teaching practice. The digital content curating was used as a way to authorize students to become protagonists in the learning process. With the objective of suggesting multi-referential methodological devices for the identification of the information literacy of students, Tiradentes University Social Communication course, of Marketing I in 2017/1. For this, it was necessary to make use of some devices as: a descriptive activity for problem solving; a questionnaire to identify the profile of informational skills; a workshop and the initial practice of content 
curation. The main result is a student with competences in the search for content, a fact that contributes to the practice of curating digital content.

Keywords: content curation; multi-referential; cyberculture; qualitative research.

\section{Introdução}

O ensino superior enfrenta em todos os lugares desafios e dificuldades sendo uma delas a melhor formação dos docentes e formar indivíduos que colaborem de forma ativa na sociedade (Unesco, 1998). Diante deste contexto da idade da aceleração de constante mudança e da complexidade digital, a necessidade de uma adaptabilidade aos novos cenários, as instituições de ensino devem estar preparadas e possibilitar que os discentes possam ser capazes de desenvolver habilidades e competências para trabalhar de forma colaborativa nos ambientes digitais. Sendo os docentes, mediadores deste processo, proporcionando ao discente a capacidade de se adaptarem de forma rápida, através de uma aprendizagem contínua ao longo da vida.

Dentro da perspectiva de Friedman (2016), uma das alternativas para minimizar o efeito avassalador da evolução da tecnologia frente a adaptação humana, é uma rápida aprendizagem. Mas o modelo de aprendizagem atual está sendo desafiado por comunidades e redes, que são mais capazes de atender às características variadas do processo de aprendizagem, utilizando múltiplas abordagens, orquestrada dentro de uma ecologia de aprendizagem (Siemens, 2003). Os alunos estão dando mais valor em saber onde encontrar informações do que em se conhecer a informação, pois as formas que aprendemos estão mudando.

Quem deve assumir este papel, de filtrar as melhores informações? No momento este é o papel do curador de conteúdos digitais, que consiste em identificar o real valor dos dados para os criadores e para quem poderá fazer uso deste dado, o usuário. O termo curadoria de conteúdo foi cunhado por Bhargava (2007), é oriundo da área do marketing, mas se observarmos as proposta teórica de Siemens (2003; 2005) sobre o conectivismo, o mesmo sugere que algumas das funções exercidas pelo professor durante o uso de tecnologias conectadas em redes digitais, enquanto facilitadoras da aprendizagem. Mesmo com a diferença de termos das áreas do marketing e da educação, o conectivismo coloca que estas funções coincidem com as funções do curador de conteúdo.

A possibilidade dos docentes e discentes compartilharem conteúdos que se encontram na internet, colabora com a ideia de se utilizar a curadoria de conteúdo digital na educação, por possuir um alto potencial colaborativo em sua realização. Sendo assim, ao utilizar destes recursos, os indivíduos, estarão contribuindo para a construção do seu conhecimento. O que a torna uma estratégia interdisciplinar, sendo necessário pensar nas necessidades dos discentes durante o seu planejamento e aplicação transversal (Clarenc, 2012).

Durante o processo de ensino e aprendizagem, os docentes e discentes, desenvolvem atividades que se assemelham as etapas de uma curadoria de conteúdo, das quais Viñas (2012) relaciona algumas: colecionar e compartilhar materiais de leituras; fomentar discussões sobre acontecimentos atuais; aprender a selecionar entre a imensa quantidade de informação disponível; avaliar e realizar crítica sobre determinada 
informação na web; conectar-se com outros estudantes e especialistas na matéria para trocar experiências; explorar e descobri o uso educativo das redes sociais; torna-se um especialista ao utilizar as publicações online como forma de se manter atualizado; e publicar as suas descobertas e conhecimento utilizando as redes sociais digitais para adquirir credibilidade.

No desenvolvimento de uma prática de curadoria de conteúdo digital voltada a educação, a "bricolagem" multirreferencial é essencial para juntar os conceitos de curadoria de diversas áreas do conhecimento, sendo possível a partir desta "bricolagem" a criação de um conceito mais adequado a área da educação. Mas o conhecimento prévio dos docentes/pesquisadores em relação as suas práticas e experiências, também contribuem para a formação deste conceito. Do ponto de vista qualitativo, o discente ao utilizar os conteúdos prévios que já possui e da interação com novas experiências, constroem novos conhecimentos, e acaba influenciando na construção do próprio indivíduo. Porém, esta condição só acontecerá se houver uma participação ativa e subjetiva de cada aluno (Sánchez-Gómez, Martín-Cilleros, Costa, \& Peñalvo, 2018).

A prática da curadoria de conteúdo digital emergiu do uso que os próprios docentes/ pesquisadores já fazem da curadoria de conteúdo no processo de ensino-aprendizagem a partir de temáticas que o interessam, ou as quais necessita aprofundar-se. $\mathrm{O}$ conhecimento do conceito de curadoria e dos elementos de uma aprendizagem ativa, de base na experiência prática proposta pelo Dewey $(1965,1989,2002)$, e o advento da cibercultura, fez emergir um novo dilema docente, como autorizar os discentes a se tornarem ativos no processo de ensino-aprendizagem, através do uso da curadoria de conteúdo digital, que orienta a buscando no ciberespaço dos conteúdos necessários para a resolução de problemas relacionados a sua profissão.

Para Cunha, Barbalho, Rezende \& Ferreira (2015), a utilização de tecnologias é um dos diversos caminhos que possibilitam a construção do conhecimento pelos alunos na atualidade, pela sua interação com os diversos meios tecnológicos disponibilizados a eles. Porém, esta construção depende profundamente das percepções e ações dos alunos, ao retomar estruturas mentais já construídas ou em construção.

Sendo assim, entende-se que a curadoria de conteúdo digital na educação deve planejar dentro de uma temática específica a Busca, Seleção, Contextualização e Compartilhamento dos conteúdos mais relevantes, para o curador, disponibilizados na web, a fim de potencializar o processo de aprendizagem de pessoas interessadas nesta temática, sejam elas: os discentes de uma turma de alunos da educação formal, ou até mesmo um sujeito fora deste universo, com objetivos de desenvolver sua aprendizagem autônoma e informal.

Este texto propõe enquanto objetivo de pesquisa, sugerir dispositivos metodológicos multirreferenciais para a identificação do perfil das competências informacionais dos discentes, da disciplina de Marketing I em 2017/1, do curso de Comunicação Social, com habilitação em publicidade e propaganda de uma Universidade particular. 


\section{A pesquisa qualitativa multirreferencial}

Ao propor uma prática que envolve o processo de ensino e aprendizagem em espaços de redes digitais, os participantes da pesquisa devem encará-la de forma diferente, pela característica da de constante mudança da cibercultura. Tendo em vista que estas mudanças impactam a todos os autores envolvidos, que são consumidores e criadores desta cultura. Na qual exige uma bricolagem de metodologias que sejam capazes de elucidar todas as mudanças que irão ocorrer durante a pesquisa (Santos, 2005).

Muitas vezes é mais confortável ao pesquisador adotar uma metodologia fechada, daquelas que não permitem qualquer tipo de mudança durante a realização da pesquisa, mesmo diante de contribuições que suscite novos caminhos. Borba (1998) alerta para a necessidade de se esquivar do conforto das ditas "metodologias prontas", sendo necessário o exercício de "bricolagem" durante o processo de criar e fazer ciência, evitando o caminho da "metodologia pronta", fechada, para uma metodologia que se adequa aos fenômenos estudados.

Acompanhando as colocações de Borba (1998), na pesquisa qualitativa multirreferencial, o método é influenciado pelo objeto de pesquisa, diante das interações do sujeito e objeto, que os expõe e modificam, da própria concepção do professor/pesquisador, ao trazer os seus conhecimentos prévios para a concepção da pesquisa. Estas possibilidades de interações no método são importantes, mas não se deve abrir mão do processo de se "fazer e criar ciência", definindo muito bem os seus procedimentos. Legitima-se a necessidade da "bricolagem" como uma postura do pesquisador frente a decisão metodológica, diante da complexidade que envolve o mundo pesquisado, e da necessidade de adaptação das técnicas as circunstâncias da pesquisa (Borba, 1998).

Partindo do imperativo de se pautar em novas práticas de pesquisa, para que se possa compreender criticamente a complexidade que envolve a realidade das pesquisas em educação em ambientes digitais, adotou-se a abordagem multirreferencial de Ardoino (1990; 1993; 1998) que exalta a "exuberância", a "abundância" e toda a "riqueza das práticas sociais" as quais são responsáveis por desautorizar a utilização da "decomposição-redução" adotada pelas "análises clássicas". Percebe-se nas "análises clássicas" uma tentativa de homogeneização dos dados, por conta desta "decomposiçãoredução", ao invés de uma articulação dos dados de forma heterogênica e plural com a complexidade da vida moderna.

Sendo assim, a abordagem multirreferencial, coloca em cheque a forma de construção de conhecimento da "racionalidade moderna cartesiana", no qual impõe de forma crucial o distanciamento entre sujeito-objeto durante o processo de construção de conhecimento (Martins, 1998). No processo de construção de conhecimento para uma abordagem multirreferencial, a identidade, as trajetórias, os desejos e os estímulos do docente/ pesquisador irão determinar a forma de construção destes conhecimentos. Da mesma forma acontece durante a curadoria de conteúdo, onde tais fatores irão influenciar como o indivíduo realiza a seleção do conteúdo e a sua contextualização. No processo de dar sentido, o curador precisará utilizar os seus conhecimentos prévios sobre a temática, estes que durante a curadoria serão transformados em novos conhecimentos. 
Ao adotar a abordagem multirreferencial, não significa uma renúncia ao rigor científico, mas uma compreensão dos fenômenos educacionais através de uma pluralidade de olhares (Martins, 1998). Sendo assim, todas as decisões epistemológicas adotadas para compreender os fenômenos educativos com base multirreferencial, jamais podem ser induzidas apenas para satisfazer o método. O pesquisador deverá sempre fazer o uso de seus referenciais teóricos e metodológicos, das suas representações sociais, das suas escolhas de análise e principalmente das falhas (Giust-Desprairies, 1998).

O docente/pesquisador ao adotar a abordagem multirreferencial, deve ser um observador presente e atuante em todos as etapas da pesquisa, assumindo assim uma atitude mais implicada com a possibilidade de modificar o olhar sob as situações de ensino e aprendizagem, em busca de uma prática desejada (Macedo, Barbosa, \& Borba, 2012). Pois diante da complexidade do olhar multirreferencial, o pesquisador enquanto observador do objeto e do seu contexto, deve ser capaz de reagir e de transformar (transforma-se) no constante processo de negociação com os outros. Essa atitude observadora e atuante também faz parte do processo de curadoria, que deve analisar criticamente os conteúdos, dentro da complexidade que lhe é peculiar. Esta atitude se transforma a cada conteúdo curado, seja pela capacidade de ir de encontro a um determinismo estabelecido, ou de se adaptar a determinada situação (Chagas, Linhares, \& Mota, 2019).

\subsection{Sistematização da experiência}

A pesquisa foi desenvolvida com os discentes do curso de Comunicação Social, com habilitação em publicidade e propaganda, na disciplina Marketing I (2017/1), sendo uma turma a tarde com 22 discentes e uma turma da noite com 37 discentes. Com o objetivo de identificar o perfil e as necessidades das competências informacionais para autorizar os discentes a se tornarem ativos no processo de aprendizagem, através do uso da curadoria de conteúdo digital.

A temática de Marketing no curso de Comunicação Social, com habilitação em publicidade e propaganda, é composta de Marketing I ( ${ }^{\circ}$ período), Marketing II ( $4^{\circ}$ período) e Marketing III ( $5^{\circ}$ período). As disciplinas de Marketing são importantes na formação do discente de publicidade e propaganda, pois a área do marketing é a responsável dentro da estrutura organizacional da empresa sobre as decisões de publicidade e propaganda, e de outras deliberações da comunicação social da empresa.

Foram utilizados dados secundários do Ministério da Educação e Cultura, sobre as diretrizes para o curso pesquisado, sendo estes dados estatísticos referentes ao número de cursos e alunos no Brasil. Também usamos dados estatísticos fornecidos pela coordenação dos cursos de Comunicação Social sobre os alunos do curso com habilitação em publicidade e propaganda.

\subsection{Procedimentos, instrumentos e estratégias utilizadas}

Na prática cotidiana da sala de aula sempre surgem situações inusitadas, que levam a uma mudança de execução das práticas outrora planejadas. Estas situações são contempladas pela abordagem multirreferencial, pois é necessário o docente /pesquisador estar atento aos detalhes peculiares a uma pesquisa ação/intervenção durante a prática docente, só assim será possível definir e preparar os dispositivos que atendam a pesquisa. 
O conjunto de dispositivos criados e planejados durante o fazer pesquisa, composto por práticas pedagógicas adotadas em sala de aula no processo de ensinar e aprender, foi denominado por Cibercuradoria Digital.

No processo de análise e identificação dos participantes, optou-se por manter a privacidade de cada indivíduo, sendo identificado como [Curador Nn] (Curador=discente; $\mathrm{N}=$ número para diferenciar o discente; $\mathrm{n}=$ turma noite e $\mathrm{t}=$ turma tarde), assim sendo possível a diferenciação entre os discentes (Curador 1n, Curador 1t, ... Curador Nn, Curador Nt), para o docente (professor/pesquisador).

Dentre os dispositivos criados e utilizados na pesquisa, temos: uma atividade descritiva para resolução de problema prático; um questionário para identificar o perfil das competências informacionais dos discentes; uma oficina de curadoria de conteúdo; e a prática inicial de curadoria de conteúdo.

A primeira atividade descritiva foi realizada em 17/05/17 (turma da tarde) e 18/05/17 (turma da noite), que fora proposta no Google Classroom, uma plataforma digital do Google onde o professor pode postar atividades, avisos, materiais complementares (texto, vídeo, áudio etc), como os discentes já faziam uso da plataforma não foi necessário explicar a sua utilização. A atividade descritiva foi uma vaga de estágio na área de marketing. O problema sugerido é que o aluno não tinha o conhecimento básico necessário para poder iniciar as suas atividades na empresa. Para a solução do problema, a empresa iria disponibilizar uma sala com notebook (conectado a wifi da empresa), durante o período de dez dias (com oito horas diárias) para que o discente pudesse aprender mais sobre marketing. Diante da situação problema, foi solicitado que cada discente descrevesse de forma detalhada a sua estratégia para poder aprender sobre os conceitos básicos de marketing e montar a sua apresentação final. Cada indivíduo teve o tempo de trinta minutos para desenvolver e postar a sua estratégia.

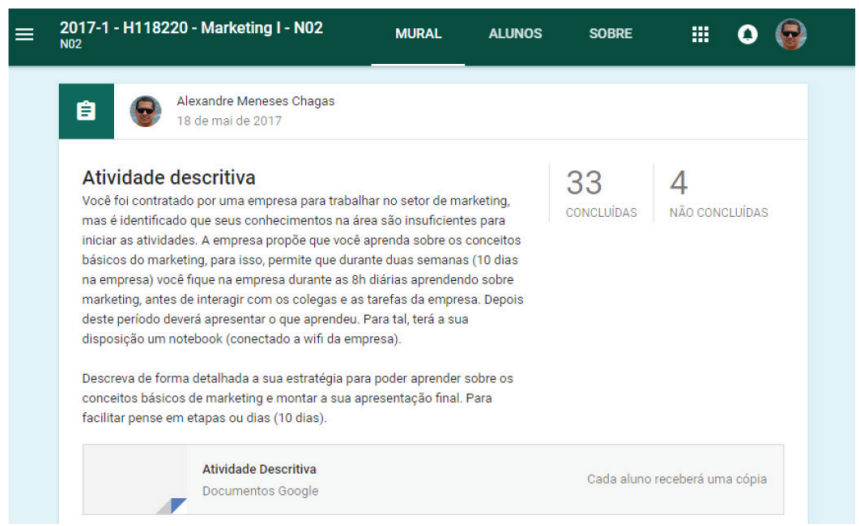

Figura 1 - Tela da atividade descritiva proposta

Uma forma de facilitar a análise dos dados referentes às repostas dos discentes, o professor/pesquisador deve estar atento, para identificar algum "corpus flutuantes" durante a construção coletiva dos dados, sendo assim possível identificar necessidade de modificação das propostas inicialmente planejadas. 
A ideia é aprender sobre os dados construídos durante a pesquisa. Porém, a prática mais comum é a que após a pesquisa, realiza-se a leitura completa das narrativas. Dessa forma, tanto durante a realização das experiências (atividades práticas), como após o término da pesquisa, os dados foram lidos e relidos, a fim de identificar o que os participantes querem expressar e mapear em categorias de análises.

Pois, somente após as várias interações com as narrativas construídas durante as experiências, emergiram acontecimentos e/ou novos significados, que podem ser contraditórios, ou não ao percebido durante a reflexão do professor/pesquisador na execução das práticas (Santos, 2014).

Para Ausubel (2003) e Santos (2014), é a partir da complexidade do olhar subjetivo do professor/pesquisador, da interpretação objetiva das narrativas e das práticas, que surgem, se estabelecem e ao mesmo tempo se atualizam as noções subsunçoras, conceito criado por Ausubel (2003) para definir parte de um conteúdo, sendo este o conhecimento prévio que o indivíduo já possui. Ao integrar novas informações a este conhecimento prévio, para assim significar a informação e transformá-la em um novo conhecimento. Essas noções subsunçoras se tornam as categorias de análise, e tendem a se modificar (evoluir), desde o seu momento inicial, da proposta de uma pesquisa, proposta esta que surge das ansiedades do professor/pesquisador em relação às suas experiências e práticas. Esta modificação é possível pela dinâmica da pesquisa, pelas questões teórico-práticas que irão confirmar ou confrontar-se com as práticas e experiências dos participantes da pesquisa (Santos, 2014).

A escolha do software de análise qualitativa webQDA (www.webqda.net), se deu por ser um software disponível na nuvem, não precisa instalar no computador, basta o acesso à internet e pela sua forma de arrumar os dados, que segundo Neri de Souza, Costa e Moreira (2011) divide esta estrutura em três partes: 1) Fontes, 2) Codificação e 3) Questionamento, conforme figura 2, a seguir.

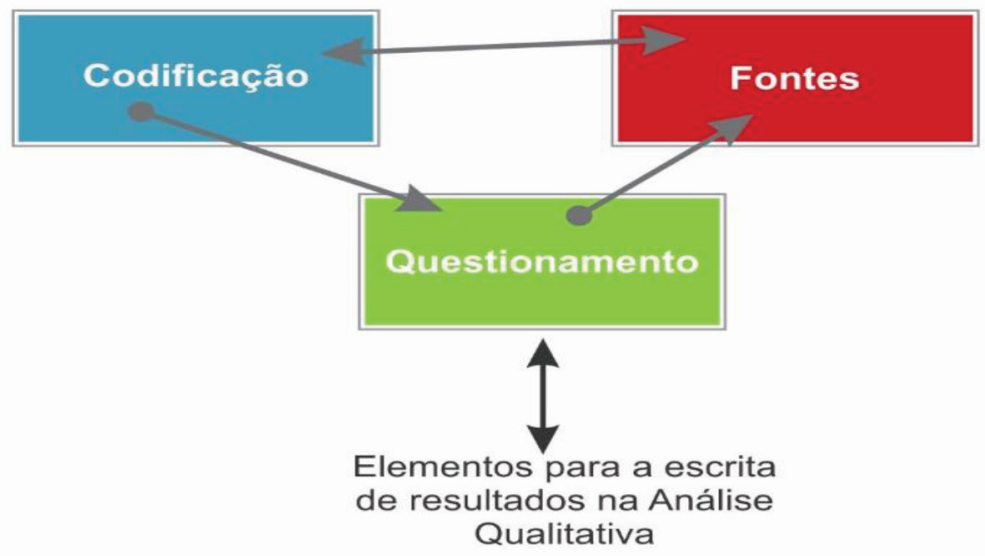

Figura 2 - Estrutura do webQDA, adaptado de Neri de Souza, Costa \& Moreira (2011, p. 53) 
No Sistema de Fontes, local onde são organizados os dados em diferentes formatos, como: texto, imagem, vídeo ou áudio. No caso desta pesquisa foram em forma de texto, os dados qualitativos da atividade descritiva. Na fase de Codificação ele possibilita criar categorias de análises e relacionar parte dos textos a cada categoria a qual pertence, como pode ser observado na figura 3, quando procuramos, no processo de análise relacionar alguns trechos das estratégias dos alunos a categoria "Aprender".

Estas fases são as iniciais do processo de análise de dados utilizando o webQDA, uma vez que os dados estão cadastrados e categorizados, é necessária a interligação destes dados com as suas codificações. Após toda categorização o professor/pesquisador poderá utilizar a terceira e última parte, o Sistema Questionamento. Neste momento é possível a realização de questionamentos da pesquisa, no qual se faz a relação entre as fontes e a codificação.

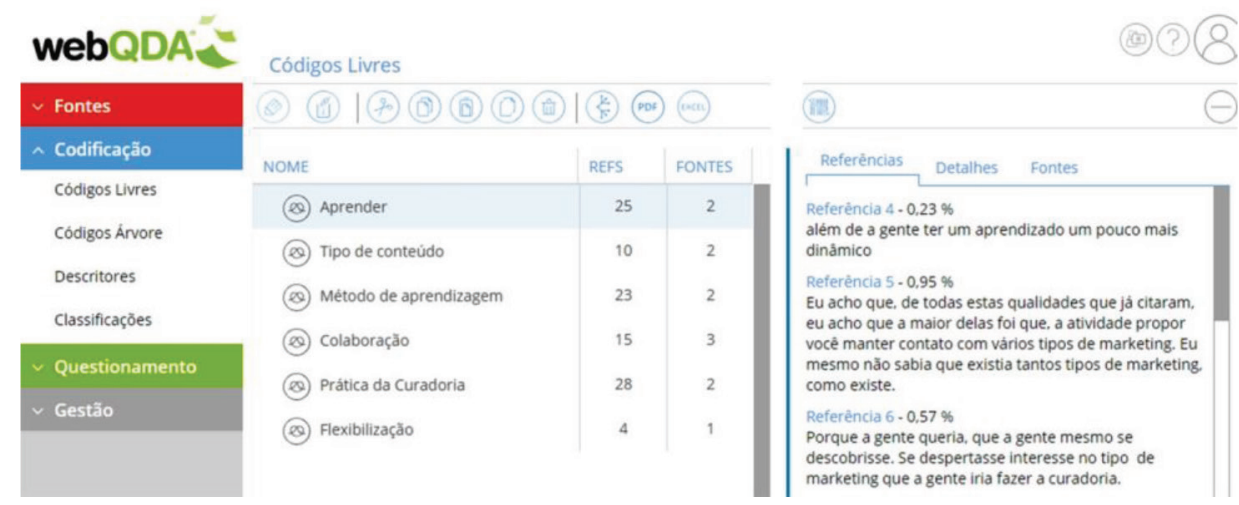

Figura 3 - Exemplo dos trechos relacionados a categoria “Aprender”, utilizando o webQDA

É no ato do questionamento que o software webQDA facilita a atividade do professor/ pesquisador. O questionar os dados é considerada a principal função do professor/ pesquisador, independente da fase de sua pesquisa e principalmente na análise e interpretação dos dados (Bardin, 1977). Assim, a utilização de recursos digitais, tanto na captura dos dados, como durante o processo de tratamento e análise, são imperativos da pesquisa na cibercultura.

O fato da maioria dos participantes terem a prática de utilizar o Google como buscador padrão de informações na internet, esta acabou sendo a estratégia inicial que utilizariam na busca de informações disponíveis na internet.

Inicialmente pesquisaria no Google sites diretos e de fácil explicação. Após entender o básico de Marketing, iria a busca de amigos graduados e que exercem a área para pedir tópicos de maior importância para pesquisar. [Curador 1n] 
Tendo a possibilidade de adquirir conhecimento sobre a nossa área de atuação eu procuraria embasamento em sites, comunidades, canais de Youtube, guias e fóruns sobre o assunto, além de procurar alinhar com os conhecimentos na vida acadêmica, com os professores que tenho acesso. [Curador 1t]

Porém, na estratégia dos curadores [1t e 1n], eles iriam além do buscador Google, ao colocar o Youtube como outra fonte de pesquisa. E seguindo os preceitos do conectivismo de Siemens (2005) e Downes (2006), eles colocaram em ampliar os locais de buscas com espaços virtuais diferenciados, como em fóruns e/ou comunidades, por serem locais onde se tem a participação de "nós especializados", pessoas que detêm experiência sobre a temática abordada. Na abordagem dos curadores [Curador 1n], [Curador 1t] e o [Curador 5n] "Quando dúvidas surgissem, ia fazer consultas com professores online.". Além dos especialistas, seriam utilizados como recursos livros, tanto na versão impressa, quanto na versão on-line, como relatado pelo [Curador 13t].

Já a importância de uma conexão rápida, abordado pelos curadores [2t, 9t e 14t], na perspectiva de que assim poderia ajudar no momento da pesquisa das informações, dos estudos, da diversão, fazendo com que as atividades na internet possam ser mais práticas e rápidas. O [Curador 2n] ainda enfatiza que "Todos lá em casa trabalham/ estudam com a ajuda da internet.", demonstrando a penetrabilidade e o grau de dependência da internet na vida daqueles que vivem em seu lar, características forte da teoria do conectivismo.

$\mathrm{Na}$ fala dos [curadores 5 t, 8t e 15t] nota-se que estar conectado a todo momento passou a ser uma necessidade, o que corrobora com a necessidade de uma conexão veloz. A colocação do [Curador 15t] "Hoje as coisas acontecem em questão de segundos e, mesmo que a gente não queira, a sociedade nos cobra conectividade.", demonstra que o apelo da sociedade conectada faz com que mesmo não sendo do seu interesse estar sempre conectado, se sente pressionado pelas atividades que só podem ser realizadas de forma on-line.

No discurso dos curadores [4n, $7 \mathrm{n}$ e 21n] fica presente a etapa do planejamento da curadoria de conteúdo, quando afirmam que utilizariam a organização do estudo para poder ter um melhor aproveitamento do tempo. Até este momento os participantes não tinham o conhecimento do conceito de curadoria de conteúdo, mas já demonstravam que agiam conforme algumas práticas da realização de uma curadoria. Quando o [Curador $7 \mathrm{n}$ ] coloca que iria adotar a estratégia de estudar por tipos de conteúdo, informando o espaço virtual no qual iria realizar a busca para cada tipo de conteúdo, além do tempo específico para cada atividade. Facilitando assim o desenvolvimento das atividades práticas de curadoria. O [Curador 21n] foi além da definição do plano de estudo, ele definiu as suas metas diárias, demonstrando interesse e uma necessidade de controle para se atingir o aprendizado.

O vídeo por ser considerado por eles uma forma fácil de assimilar o conhecimento, foi o tipo de conteúdo mais suscitado pela maioria em suas práticas. O vídeo é composto por várias linguagens (visual, falada, musical, sensorial e escrita) que ao agirem em conjunto potencializam o conteúdo, por utilizar todos os sentidos para nos atingir de diversas maneiras. Estas características do vídeo seduzem durante o entretenimento, levando 
o indivíduo a outra realidade (imaginária), além de informar em diferentes tempos e espaços (Moran, 1995).

No terceiro dia juntaria todos os conceitos, criando um problema para que eu pudesse aplicar uma estratégia de marketing solucionando este problema. [Curado 24n]

E nas duas horas restantes tentaria criar situações para resolver com o que havia aprendido naquele dia. [Curador 31n]

Após entender, buscaria alguma atividade na internet para avaliar o que foi aprendido nesse período. [Curador 38n]

A afirmação do [Curador 39n] "Por que a melhor forma de aprender é exercitando.", corrobora as colocações anteriores dos curadores [24n, 31n e 38n], no qual uma forma de aprender é exercitando, ou pondo em prática o que acabará de conhecer, podendo ser através da resolução de problemas. Assim é possível identificar quais conteúdos realmente foram compreendidos e quais necessitam de um reforço. Tendo em vista que a nossa vida é um constante sofrer e experimentar, tecendo assim todas as experiências necessárias para uma aprendizagem contínua, pois é através das experiências reais, que adquirimos a nossa aprendizagem de vida (Dewey, 1965).

Uma das práticas apresentadas pelo [Curador 8t] se assemelha a necessidade de contextualização da curadoria de conteúdos digitais na educação, quando diz: "Faria resumos diários do que foi aprendido tomando nota dos pontos mais importantes, isso me ajudaria na apresentação.”, esta prática aparece nas falas de outros curadores. No entanto, a contextualização não é apenas um resumo, mas uma indicação do que o curador irá selecionar de interessante no conteúdo, partindo da sua visão de mundo em relação ao tema curado. Para os discentes que tem a prática de realizar resumos, passar a fazer contextualização dos conteúdos é algo mais fácil, por possuírem o hábito de escrever sobre o que estão aprendendo.

Finalizada a primeira atividade sobre o estágio em marketing, foi disponibilizada uma pesquisa por meio de um questionário digital, o qual teve o tempo médio de resposta de quinze minutos. Este questionário foi direcionado para tentar identificar o perfil das competências informacionais dos discentes. Este questionário, foi aplicado após a atividade descritiva do estágio em marketing para não induzir nas respostas da atividade descritiva e como forma de complementar o entendimento sobre este perfil dos discentes. Esta pesquisa foi através da plataforma (https://surveymethods.com/), plataforma online que disponibiliza questionários com questões abertas e fechadas. Pois, ao fazer uso de sistemas de pesquisa on-line, a etapa de construção dos dados é facilitada, tendo em vista que todos os dados ficam catalogados e podem ser organizados de forma prática pelos sistemas. Além de ajudar na fase de análise dos referidos dados, por possibilitar uma leitura dos dados de forma geral ou por indivíduo.

A proposta do formulário de pesquisa foi ser dividido em dimensões, para poder tratar de cada área em separado, evitando confusão dos respondentes. O formulário foi dividido em oito dimensões com questões fechadas e apenas uma aberta. Assim, optou-se por dividi-las em páginas, sendo cada dimensão disponibilizada em uma seção diferente. 
Apesar de possuir a versão gratuita, optamos pela versão paga, pois, possibilita a realização de testes lógicos. Além de que na fase de análise dos dados ser possível criar critérios de filtragem, ver figura 4. Caso deseje cruzar informações de quem respondeu à pergunta dois (o item b) e a pergunta quatro (o item c), ele irá filtrar e mostrar apenas os respondentes que escolheram esta relação, o que facilita na fase de análise a correlação de respostas.

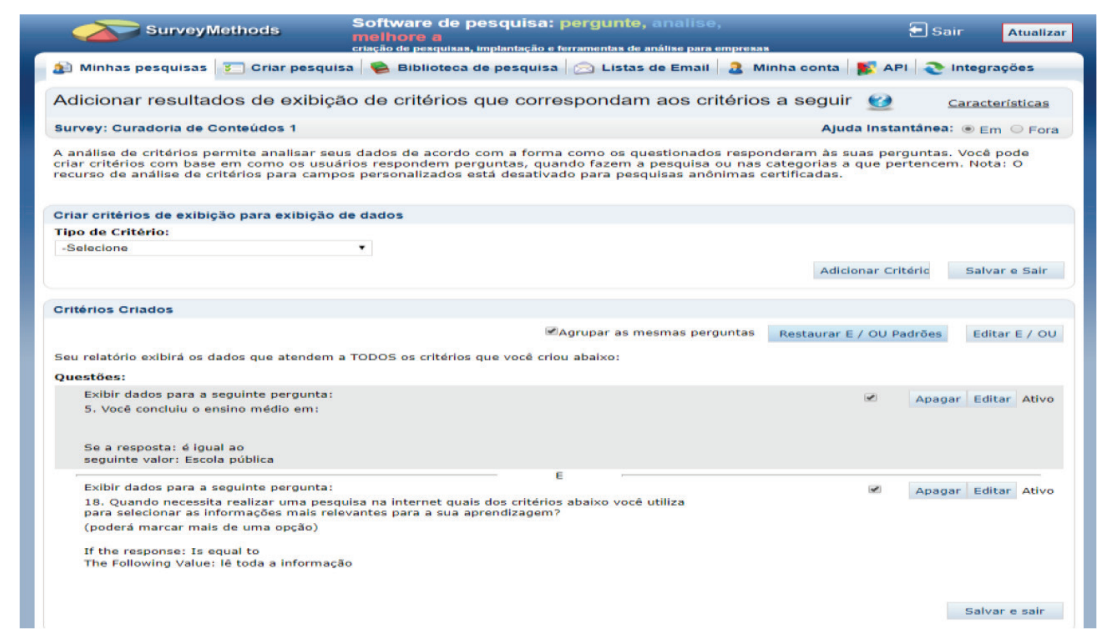

Figura 4 - Tela de correlação dos dados da pesquisa utilizando o surveymethods.com

Antes da utilização do formulário o professor/pesquisador procurou gerar interesse dos discentes, pois para Barbier (2004) ao se tornar uma parte ativa do processo de pesquisa, os discentes estão abertos a expor suas visões de interação, pois estão construindo coletivamente, juntamente com o professor/pesquisador, mesmo que estejamos envolvidos tanto de forma emocional, racional e sensorial.

Na primeira dimensão, com 20 perguntas para a identificação sobre o tipo de acesso e o comportamento de acesso do indivíduo. Nesta dimensão que estava a única questão aberta. A partir da segunda dimensão a intensão é uma Autoavaliação das CompetênciasHabilidades que cada um acredita possuir. A segunda dimensão para identificar a "Inclusão Digital", com 10 itens; a terceira sobre "Pesquisa da Informação", com 5 itens; a quarta sobre a "Avaliação da Informação", com 5 itens; na quinta foram abordados o "Processamento, Comunicação e Difusão da Informação", com 6 itens; a sexta focou a "Aprendizagem", com 10 itens; a sétima "Formação Especializada", com 6 itens e na oitava e última dimensão a "Ética da Informação", com 6 itens.

Como não dispúnhamos de tempo para testar o formulário com uma amostra, optamos em validar o questionário com dois professores do curso de Comunicação Social com Habilitação em Publicidade e Propaganda (Unit), L. R., publicitário, professor universitário e mestre em comunicação e, C. N., publicitário, professor universitário e mestre em educação, onde foi explanado sobre a proposta da pesquisa e solicitado um parecer. Os dois pareceres, críticos e construtivos foram de muita valia. Diante das 
sugestões, foi realizada uma modificação no questionário deixando-o mais adequado para atender a necessidade de mapear o perfil dos discentes.

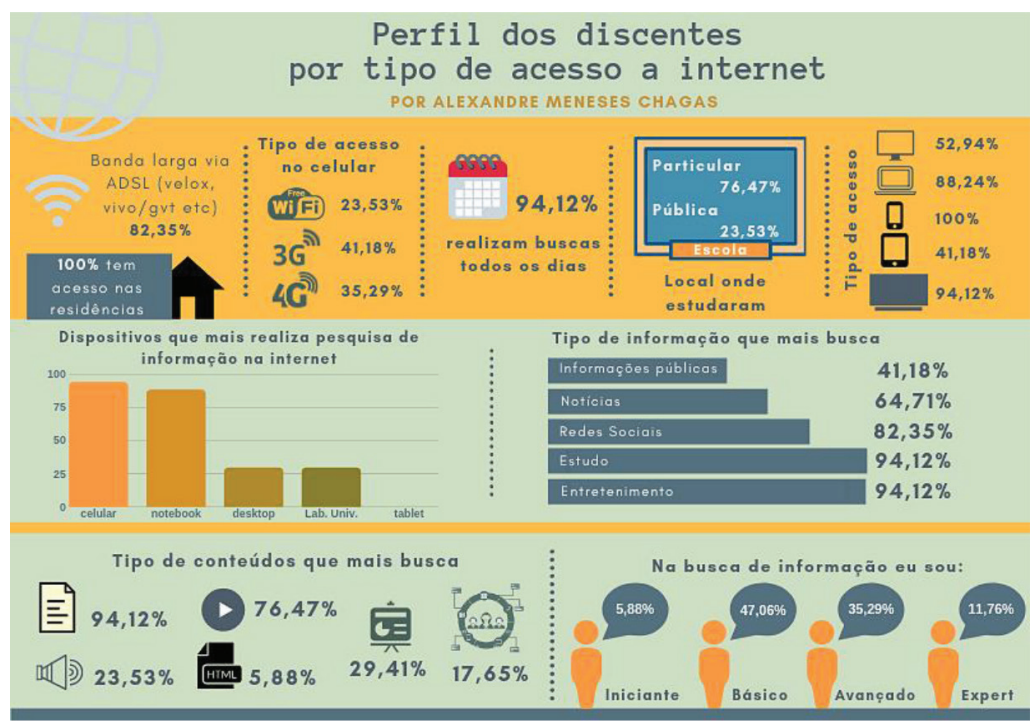

Figura 5 - Infográfico elaborado com os dados da pesquisa de perfil

Após a realização da atividade descritiva e aplicação do questionário, foi realizada a leitura flutuante "corpus flutuantes", procurando mapear necessidades de modificação da oficina sobre curadoria de conteúdo, que seria posteriormente ministrada para os discentes. Ao utilizar os dados para modificar um dos métodos utilizados na pesquisa, colabora com a proposta de Borba (1998) em relação à pesquisa qualitativa multirreferencial, pois diante das possíveis interações do sujeito com o objeto, o método poderá sofrer modificações pelo objeto de pesquisa, diante de suas necessidades.

A oficina foi desenvolvida nos dias 24/05/17 (tarde) e 25/05/17 (noite), com apresentação do modelo de curadoria de conteúdo digital, na disciplina de Marketing I (2017/1), com uma parte teórica e outra prática. Na turma da tarde participaram os 22 discentes da disciplina e na turma da noite participaram 35 discentes. Os dois discentes, da turma da noite, que não participaram da parte teórica, fase inicial da oficina, se integraram na atividade prática a um grupo. Durante a atividade prática, o grupo explicou a proposta da curadoria para os dois colegas. Em determinado momento o dissente/pesquisador também dirimiu dúvidas destes discentes e de outros.

Todo material utilizado durante a oficina de curadoria digital na educação fora disponibilizado aos participantes antes do seu início, desta forma ele poderiam acompanhar o que estava sendo explanado, além de ter o material para posterior consulta. Dentre as temáticas abordadas a primeira foi sobre a necessidade atual da curadoria de conteúdo digital, diante da quantidade de dados e informação disponibilizada no espaço virtual (internet), o conceito de curadoria de conteúdo indo 
até a sistematização da prática da curadoria de conteúdo digital. A fim de não deixar a oficina apenas conceitual, foram realizadas práticas de técnicas de busca na internet, mobilizando os participantes em uma competição entre eles na busca de informações. Dentro da proposta de Lévy (2010) ao realizar uma caçada a informação pontual. Outro momento de prática, foi na demonstração e uso de alguns aplicativos para a realização da busca e seleção dos conteúdos.

Após a realização da oficina, nos dias 29/05/17 (tarde) e 30/05/17(noite), foi proposta uma atividade prática de curadoria de conteúdo digital em grupo, com a temática de "Branding", esta prática foi mediada pelo pesquisador/professor com a proposta de mobilizar o que fora aprendido durante a oficina e identificar as possíveis dificuldades na realização da curadoria de conteúdo digital por parte dos discentes.

Durante esta prática se fez necessário explicar como postar as curadorias no aplicativo Evernote, é um aplicativo que facilita a coleta de conteúdo na internet, além da gestão destes conteúdos, possibilitando a sua edição e compartilhamento, site proposto pelo professor/pesquisador para a atividade prática. Como a maioria dos discentes não dominavam a utilização do Evernote, foi demandado um tempo para explicar como: coletar, organizar e compartilhar a informação no Evernote. Essa etapa demandou vinte e quatro minutos, um tempo superior ao qual havia sido planejado pelos pesquisadores (cerca de quinze minutos).

Depois deste momento prático da realização de curadoria em grupo, no mesmo dia foi solicitada uma curadoria individual, a qual deveria ser finalizada nos dias 5/6/17 (tarde) e 6/6/17 (noite) sobre "Marketing de Guerrilha", mas que poderia ser realizada algumas etapas fora da sala de aula, sendo deixado apenas o fechamento e as dúvidas para este dia.

As primeiras curadorias, realizadas entre 29 e 30/05/17 sobre "Branding" e a finalizada nos dias 5/6/17 e, a de 6/6/17 sobre "Marketing de Guerrilha", serviram para que os discentes adquirissem as habilidades imprescindíveis para manipular a informação e realizar a curadoria de conteúdo. Inicialmente a principal dificuldade foi entender a necessidade de contextualizar cada conteúdo curado, mas como as curadorias foram mediadas pelo pesquisador/professor, a cada momento de dúvida ou questionamento eram sanados de imediato. Estas atividades serviram de preparação para os envolvidos na pesquisa estrarem aptos a realizarem de forma independentes as suas curadorias de conteúdos digitais. Possibilitando uma aprendizagem ativa e significativa.

Dentro da proposta da construção do conhecimento no olhar plural e heterogêneo da multirreferencialidade, alguns elementos irão determinar o agir do professor/ pesquisador e dos pesquisados, onde a sua identidade, trajetórias, desejos e estímulos irão determinar como este novo conhecimento será formado. Sendo assim, um ir e vir no "fazer ciência" diante de cada necessidade a ser pesquisada.

\section{Conclusões}

Uma das características de Ardoino, apontada por Berger (2012), é a de que ele nunca vai do conhecido ao desconhecido, sempre se deixa invadir pelo desconhecido, e assim 
relfete sobre ele, fazendo com que a prática (experiência) seja o ponto inicial para uma reflexão. Assim sendo, o planejamento deve ser mínimo, para evitar fechar as possibilidades de se encontrar com o desconhecido e não estar aberto para modificar a sua metodologia.

Diante do objetivo proposto, ao tentar criar dispositivos metodológicos que atendessem as necessidades para uma identificação do perfil e as necessidades das competências informacionais dos discentes. Propomos uma atividade descritiva, que colocou os discentes diante de uma possibilidade real e suscitava deles a resolução de problema que poderiam efetivamente ocorrer na realidade. Percebeu-se uma motivação maior na participação e contribuiu para entender como cada um deveria agir diante da referida situação problematizada, além de desenvolver competências informacionais tais como: realizar as buscas e como considerar quais fontes são as mais confiáveis para ampliar o seu aprendizado.

Os dois primeiros dispositivos da pesquisa sugeridos, tanto o questionário online e a atividade descritiva, foram fundamentais para a formação do professor/pesquisador, pois pode perceber que algumas estratégias anteriormente planejadas necessitavam de ajustes para estarem adequadas ao perfil destes discentes. Além de ser possível identificar a melhor forma de abordar a temática da curadoria de conteúdo, dentro da expectativa destes discentes. A cada dispositivo utilizado na pesquisa, foi necessário todo um investimento por parte do professor/pesquisador em dominar as técnicas destes dispositivos, além das bases conceituais necessárias para a sua utilização. Sendo assim, o período da pesquisa foi também uma formação do docente, não só no processo de utilizar, analisar, conceber os dispositivos, mas dos conhecimentos necessários para mobilizá-lo.

A situação problema da atividade descritiva de estágio contribuiu para perceber que os discentes já possuem uma prática voltada para a curadoria de conteúdo digital. As estratégias ora colocadas por eles demonstram conhecimentos de atividades desempenhadas pelo curador, facilitando assim a compreensão dos conceitos e práticas de curadoria. Mas, foi importante para ajustes na oficina proposta, diante das colocações dos discentes e de suas práticas cotidianas na internet.

Durante a oficina focou-se na forma de classificar uma fonte como confiável e nas melhores estratégias de se realizar busca, inclusive com a utilização de softwares disponíveis na internet. A busca mais rápida ajuda no processo da curadoria de conteúdo digital, tendo em vista que se deve realizar várias buscas para depois selecionar o que será curado.

Na abordagem multirreferencial de Ardoino (1993; 1998) o conceito de agente-atorautor, é uma condição necessária para o pesquisador, assim sendo este pequisador que é um ser "coletivo" acaba sendo composto por todos os sujeitos participantes, atores e autores da pesquisa. De tal modo, é necessário uma consciência por parte dos docentes de permitirem aos seus discentes a possibilidade de se autorizar, e ao mesmo tempo incentivar que cada indivíduo possa ser capaz de ser seu próprio autor. Uma vez imputado aos discentes o poder de se autorizar, este será capaz de realizar a sua própria formação através do processo de construir a curadoria de conteúdo digital, e tornar-se autor deste processo de formação contínua. 


\section{Referências}

Ardoino, J. (1990). Les postures (ou impostures) respectives du chercheur, de l'expert et du consultant. In Actes du coloque Les Nouvelles Formes de la Recherche em Éducation. Retrieved March 12, 2018 from: https://goo.gl/f8kUys

Ardoino, J. (1993). L'approche multireferentielle (plurielle) des situations educatives et formatives. In L'approche multiréférentielle en formation et en sciences de l'éducation, Pratiques de formation (analyse) (pp. 1-14). Retrieved from http:// probo.free.fr/textes_amis/approche_multireferentielle_situations_educatives.pdf

Ardoino, J. (1998). Abordagem multirreferencial (plural) das situações educativas e formativas. In R. B. de Camargo (Trans.), Multirreferencialidade nas ciências e na educação (pp. 24-41). São Carlos: EdUFSCar.

Ausubel, D. P. (2003). Aquisição e Retenção de Conhecimentos: uma perspectiva cognitiva. Lisboa: Paralelo.

Barbier, R. (2004). A pesquisa-ação. Brasília: Liber Livro.

Bardin, L. (1977). Análise de conteúdo. Retrieved from https://goo.gl/rC6Z3Z

Bhargava, R. (2007). Librarians Blogging and The Birth of Library 2.o. Influential Marketing Blog. Retrieved March 1, 2017, from https://goo.gl/kKgkAT

Borba, S. (1998). Aspectos do conceito de multirreferencialidade nas ciências e nos espaços de formação. In J. G. Barbosa (Ed.). Reflexão em torno da abordagem multirreferencial (pp. 11-19). São Carlos: EdUFSCar.

Chagas, A. M., Linhares, R. N., \& Mota, M. F. (2019). Um olhar plural e heterogêneo na prática da curadoria de conteúdo digital na educação. In Livro de Actas CIAIQ 2019 (Vol. 1). Retrieved from https://proceedings.ciaiq.org/index.php/CIAIQ2019/ article/view/2244

Clarenc, C. A. (2012). La curación de contenidos y la colaboración en la construcción del PLE y los conocimientos. In Clarenc, C. A., Humano Digital. Retrieved July 12, 2017, from: https://goo.gl/f5z3wh

Cunha, A. de L. da, Barbalho, M. G. da S., Rezende, L. T. de, \& Ferreira, R. M. (2015). Matemática do ensino médio e as tecnologias de informação e comunicação nas escolas públicas estaduais de Goiás. RISTI - Revista Ibérica de Sistemas e Tecnologias de Informação, (E4), 1-15. Retrieved from http://www.scielo.mec.pt/ scielo.php?script $=$ sci_abstract\&pid $=\mathrm{S} 1646-98952015000400002 \& \operatorname{lng}=\mathrm{pt} \& \mathrm{nrm}=\mathrm{i}$ so\&tlng $=\mathrm{pt}$

Dewey, J. (1965). Vida e educação (5th ed.). São Paulo: Melhoramentos.

Dewey, J. (1989). Cómo pensamos: la relación entre pensamiento reflexivo y proceso educativo. Barcelona: Paidós.

Dewey, J. (2002). A escola e a sociedade: a criança e o currículo. Lisboa: Relógio D’Água.

Downes, S. (2006). Learning Networks and Connective Knowledge. Retrieved November 25, 2017, from: https://goo.gl/TodQms 
Friedman, T. (2016). Thank You for Being Late: An Optimist's Guide to Thriving in the Age of Accelerations. New York: Farrar, Straus and Giroux.

Giust-Desprairies, F. (1998). Reflexão epistemológica sobre a multirreferencialidade. In M. A. Ramos (Trans.), Multirreferencialidade nas ciências e na educação (pp. 159-167). São Carlos: EdUFSCar.

Lévy, P. (2010). Cibercultura (3rd ed.). São Paulo: Editora 34.

Macedo, R. S., Barbosa, J. G., \& Borba, S. (2012). Jacques Ardoino \& a Educação. Belo Horizonte: Autêntica Editora.

Martins, J. B. (1998). Multirreferencialidade e educação. In J. G. Barbosa (Ed.), Reflexão em torno da abordagem multirreferencial (pp. 21-34). São Carlos: EdUFSCar.

Moran, J. M. (1995). O Vídeo na Sala de Aula. Comunicação \& Educação, o(2), 27-35. Retrieved from https://goo.gl/jbEUot

Sánchez-Gómez, M. C., Martín-Cilleros, M. V., Costa, A. P., \& Peñalvo, F. J. G. (2018). Posicionamiento de la investigación en Ciencias Sociales. RISTI - Revista Ibérica de Sistemas e Tecnologias de Informação, (28), 102-113. Doi: https://doi. org/10.17013/risti.28.102-113

Santos, E. (2005). Educação online: cibercultura e pesquisa-formação na prática docente (Universidade Federal da Bahia). Retrieved from https://goo.gl/117Vln

Santos, E. (2014). Pesquisa-formação na cibercultura. Santo Tirso: Whitebooks.

Siemens, G. (2003). Learning Ecology, Communities, and Networks Extending the classroom. Retrieved July 12, 2017, from: https://goo.gl/kTPEMc

Siemens, G. (2005). Connectivism: a learning theory for the digital age. International Journal of Instructional Technology and Distance Learning, 2(1), s/p. Doi: https:// doi.org/10.1.1.87.3793

Souza, F. N., Costa, A. P., \& Moreira, A. (2011). Análise de Dados Qualitativos Suportada pelo Software WebQDA. In Atas Da VII Conferência Internacional de TIC Na Educação: Perspetivas de Inovação (CHALLANGES2011), 12, 49-56. Retrieved from https://goo.gl/gBuxLV

Unesco (1998). La educación superior en el siglo XXI: Visión y acción. Retrieved from https://goo.gl/tHcdp8

Viñas, M. (2012). Del caos al orden: encontrar, filtrar y coleccionar contenido educativo. Retrieved July 12, 2017, from: https://goo.gl/LB2mJt 